\title{
Antifungal Effect of Thymus Vulgaris Essential Oil and Chlorhexidine on Candida Albicans Colonies Accumulated on Removable Orthodontic Appliances: A Double- blinded Clinical Trial.
}

Arefe Kalantari khandani

Islamic Azad University Shiraz Branch

Tahereh Baherimoghadam

Islamic Azad University Shiraz Branch

Navid Naseri ( Navidnaseri@gmail.com )

Islamic Azad University Shiraz Branch https://orcid.org/0000-0002-8772-5316

Azade Kalantari khandani

Kerman University of Medical Sciences

Sadegh Nouripour-Sisakht

Yasuj University of Medical Sciences

Roja Safaeian

Shiraz University

Research article

Keywords: Removable Orthodontic Appliances, Thymus Vulgaris Essential Oil, Candida Albicans,

Chlorhexidine

Posted Date: May 15th, 2020

DOI: https://doi.org/10.21203/rs.3.rs-28434/v1

License: (c) (i) This work is licensed under a Creative Commons Attribution 4.0 International License.

Read Full License 


\section{Abstract}

Objectives: To assess the efficacy of Thymus vulgaris (T. vulgaris) essential oil to decrease the count of Candida albicans (C. albicans) accumulated on removal orthodontic appliances.

Methods: In this 2 arm parallel controlled clinical trial, Forty-four patients whose removable orthodontic appliances contaminated with $\mathrm{C}$. albicans were randomly divided into two groups for use of $\mathrm{T}$. vulgaris essential oil and $0.2 \%$ Chlorhexidine (CHX) by electronic random sampling. The $\mathrm{C}$. albicans colony count was measured at baseline (T0) and at 2 (T1) and 5 (T2) days after the intervention. Microbial samples were collected by a sterile swab from 3 spots on the internal surface of orthodontic appliances. The Friedman test was used for within-group comparisons while the Mann Whitney test was applied to compare the efficacy of T. vulgaris essential oil and CHX.

Results: No significant difference was noted in the efficacy of $2 \% \mathrm{~T}$. vulgaris essential oil and $0.2 \% \mathrm{CHX}$ in decreasing the $\mathrm{C}$. albicans colony count on removable orthodontic appliances.

Conclusion: T. vulgaris essential oil has favorable antimicrobial activity against $C$. albicans.

\section{Background}

Acrylic removable orthodontic appliances are commonly used for myofunctional therapy or simple tooth movements in children and adolescents during the prepubertal or pubertal stage. They can correct some maxillofacial problems by benefitting from the growth potential during this time period. Also, these appliances are used during the maintenance phase after completion of orthodontic treatment to maintain the results and prevent relapse [1]. Long-term daily use of removable orthodontic appliances is imperative to achieve ideal treatment results. However, this pattern of use increases the risk of accumulation of microorganisms on the surface of appliances [2]. Despite the numerous benefits of removable orthodontic appliances, their use can enhance microbial biofilm accumulation on dental surfaces and appliance components such as the clasps, springs, and acrylic base [3]. Evidence shows that use of removable orthodontic appliances can alter the oral microbial flora, increase the salivary count of Streptococcus mutans, and enhance the biofilm formation during the active treatment phase $[4,5]$. Moreover, the porosities on the internal and external surfaces of the acrylic resin base of such appliances are covered by pathogenic microorganisms mainly Candida albicans (C. albicans) [6-8].

The acrylic base of removable orthodontic appliances is made of plastic polymers, which contain carbohydrates, and attract several microbial strains such as $\mathrm{C}$. albicans that consume such polymeric materials [7, 9]. Moreover, decomposition of acrylic resin can enhance microbial biofilm accumulation [3]. Microbial biofilm contains different microorganisms that strongly adhere to each other and also to the surface. These microorganisms are located on a network of proteins and polysaccharides $[10,11]$. Also, use of removable orthodontic appliances increases the count of pathogenic microorganisms such as Streptococcus mutans, Lactobacillus, and C. albicans in unstimulated saliva of patients. Change in oral microbial flora can increase the risk of caries and periodontal disease [12-14]. 
Chlorhexidine (CHX) is the gold standard for chemical removal of microbial plaque, which is often prescribed as an adjunct to mechanical plaque removal methods. However, long-term use of chemical agents is not recommended [15-18].

Use of herbal essences for their antimicrobial properties has been previously evaluated [19-21]. Several medicinal plants such as thyme, cloves, lavender and tea leaves have been tested for disinfection of the oral cavity [22-27]. Given that medicinal plants are suitable alternatives to chemical agents, application of chemical agents can be limited to acute cases, and herbal products can be recommended for continuous long-term use by orthodontic patients during their treatment course [18].

Thymus (thyme) is an important medicinal herb that belongs to the Lamiaceae family. Thymus, Ziziphora, and Zataria are the three main genera of the Lamiaceae family. The thymus genus has 14 species in Iran, and Thymus vulgaris (T. vulgaris) is one of the most important species [33]. Thymol and carvacrol are the main constituents of T. vulgaris essence. Also, it contains tannin, flavonoids, and saponins [34]. The T. vulgaris essential oil has several pharmaceutical and therapeutic applications [25]. It also has high chance of acceptance by patients due to its favorable taste and odor, insignificant toxicity and side effects, and low cost [35].

Essential oil is the alcoholic extract with a volatile oil, which can be extracted by different techniques such as the cold-pressed extraction method, distillation, extraction by solvent, distillation under vacuum using a microwave, maceration, or extraction with absorbent oils obtained from herbal products [36]. Distillation is an important method of essential oil extraction, which is based on separating the components or substances in two phases [37]. Evidence shows that Zataria multiflora (Shirazi thyme) has suitable antimicrobial and antifungal properties for irrigation of root canals in endodontic treatment in vitro, compared with chemical irrigating solutions [38,39]. Also, Zataria multiflora essential oil is effective for disinfection of acrylic plates and orthodontic elastics in vitro [40, 41]. Favorable antifungal activity of T. vulgaris essential oil, compared with $\mathrm{CHX}$, has also been reported for disinfection of removable orthodontic appliances in vitro [42].

\section{Specific objectives and hypotheses}

This study aimed to compare the effects of T. vulgaris essential oil and CHX on C. albicans accumulated on removable orthodontic appliances. The null hypothesis was that there was no difference in Antifungal efficacy of T. vulgaris essential oil and CHX.

\section{Materials And Methods}

\section{Trial design and any changes after trial commencement}

This double-blind, single-center, parallel clinical trial with 1:1 ratio was approved by the ethics committee of Islamic Azad University, School of dentistry, Shiraz Branch (Reference: IR.IAU.SHIRAZ.REC.1397.004) 
and registered in the Iranian Registry of Clinical Trials (IRCT20180923041092N1). There were no changes to the trial after its commencement.

\section{Participants, eligibility criteria and settings:}

Patients with removable orthodontic appliances with a midline expansion screw whose orthodontic treatment had commenced 6 to 8 months earlier in the Orthodontics Department of School of Dentistry of Islamic Azad University, Shiraz Branch were enrolled in this study. The medical and dental history of patients and their oral health, dental status, type of malocclusion, dental arrangement, and oral hygiene were evaluated before the study. Of 83 candidates for participation in the study, those with large diastema or periodontal problem, patients using antimicrobial mouthwashes, those who reported antibiotic intake in the past 3 months, and patients with very poor oral hygiene were excluded. According to the inclusion and exclusion criteria, 55eligible patients were selected. The participants were briefed about the study, and written informed consent was obtained from them.

\section{Primary sampling to detect patients with C. albicans:}

One main inclusion criterion for the study was presence of C. albicans on removable orthodontic appliances of patients. Thus, a primary sampling was performed for assessment of the presence/absence of $\mathrm{C}$. albicans on removable orthodontic appliances. For this purpose, a sterile swab dipped in sterile distilled water was used to collect samples from three spots on the internal surface of the removable appliance that was in contact with the oral mucosa. The three spots were $(I)$ at the center of the appliance, (II) close to the gingival margin of teeth \#4 and \#5, or D and $E$ in the right side, and (III) close to the gingival margin of teeth \#4 and \#5, or $D$ and $E$ in the left side. The collected sample was streak cultured on a specific culture medium for $\mathrm{C}$. albicans. The plates were coded and sent to a microbiology lab for the microbial culture. Each participant was allocated a code. Of 55 patients, 44 were positive for $\mathrm{C}$. albicans and were enrolled in the study.

\section{Microbial culture:}

The Sabouraud dexterous agar containing chloramphenicol is a specific culture medium for $\mathrm{C}$. albicans [26]. Thus, the collected microbial sample was streak cultured on this culture medium, and the plate was then incubated for 24-48 h. The proliferated colonies of $\mathrm{C}$. albicans were observed on the culture medium after this time period.

\section{Staining:}

Lactophenol cotton blue dye, which is a strong dye for diagnostic staining of slides, was used for identification of $\mathrm{C}$. albicans colonies, and their differentiation from other microorganisms.

Microorganisms absorb cationic chromatophores due to their slight negative charge, which reveals the morphology of microorganisms under a microscope. For staining, two drops of distilled water were applied at the center of a sterile slide and one drop of lactophenol cotton blue dye was added to distilled water. Next, some colonies were added and dissolved in the dye using a sterile loop such that a 
homogenous suspension was obtained. Next, the slide was inspected under a microscope at $x 4, x 10, x 40$ and finally $\times 100$ magnification to identify and study the microorganisms.

\section{Intervention:}

After finding the patients with orthodontic appliances contaminated with C. albicans, patients were randomly divided into two groups of $2 \% \mathrm{~T}$. vulgaris essential oil and $0.2 \% \mathrm{CHX}$ control group.

\section{Intervention group:}

In the intervention group, the patients received T. vulgaris essential oil spray. In order to prepare the T. vulgaris essential oil, some research was conducted to find T. vulgaris with higher concentrations of thymol and carvacrol. Thus, T. vulgaris was obtained from Aliabad Tang village in Beyza city of Fars Province, Iran, and T. vulgaris essential oil was extracted by distillation. Analysis of the essence was performed by gas chromatography/mass spectrometry (GC-MS; Agilent Technologies-5975C- MS,7890A$\mathrm{GC})$ to measure the concentrations of thymol and carvacrol. A clinical trial aiming to determine the minimum inhibitory concentration (MIC) of T. vulgaris essential oil against $\mathrm{C}$. albicans reported that the MIC of T. vulgaris essential oil against C. albicans was $1.56 \%$ (equal to $15.6 \mu \mathrm{L} / \mathrm{mL}$ ). ${ }^{42}$ Thus, in this study, $2 \%$ concentration of T. vulgaris essential oil was formulated after taking into account the possibility of procedural errors and in order to increase the effect size.

In the formulation of T. vulgaris essential oil, distilled water was used as the aqueous phase, T. vulgaris essential oil was used as the organic phase, and Span 80 and Tween 80 were used as surfactants. In order to prepare $2 \%$ formulation, $2 \mathrm{wt} \%$ of a mixture of Tween 80 and Span 80 along with the essence were added to $96 \mathrm{wt} \%$ of distilled water. Regarding the order of mixing, first Tween 80, Span 80, distilled water and essence were separately weighed. Next, distilled water was added to Tween 80, and the essence was added to Span 80. Eventually, the mixture of essence and Span 80 was added to the mixture of water and Tween 80 . The final solution was mixed for 1-3 min, and sonication was performed for $15 \mathrm{~min}$ at room temperature in order for the components to form a homogenous mixture. After preparing $2 \% \mathrm{~T}$. vulgaris essential oil, it was packaged in the form of $50 \mathrm{~mL}$ sprays, which were filled with the solution using a funnel. The sprays were also coded. The patients received comprehensive instructions on how to use the sprays and also regarding daily hygienic measures. Also, comprehensive instructions for use were provided on the labels of the sprays. The patients were requested to spray the internal surface of their orthodontic appliance from $15 \mathrm{~cm}$ distance every night after washing their appliance and then rinse it again 15 min after spraying.

\section{Control group:}

The control group received $0.2 \% \mathrm{CHX}$ Najo in the form of spray with the same packaging and labeling as those administered among the test group. Similarly, the control subjects were provided with thorough 
instructions on how to use the spray and perform daily hygienic measures. Also, comprehensive instructions for use were provided on the labels of the sprays. The sprays were then coded.

\section{Outcomes (primary and secondary) and any changes after trial commencement}

The second microbial sampling was performed in both groups at baseline prior to the commencement of clinical trial (T0), and at 2 (T1) and 5 days (T2) after using the sprays. A sterile swab was used for sampling from three spots of the appliance as explained earlier for the first sampling. The person preparing and providing the sprays to the participants and those responsible for culture and diagnosis of the slides were all blinded to the group allocation of samples. There were no changes to the trial after its commencement

\section{Sample size calculation:}

A total of 40 participants were required to achieve $85 \%$ power (instituted by G power, version 3.0.1; Franz Faul universitat, Kiel, Germany) and detect significant differences considering the effect size of 0.47 ( $P<$ 0.05). Considering the possible dropouts, the sample size was increased to 44.

\section{Interim analyses and stopping guidelines}

Not applicable.

\section{Randomization:}

Before the trial commencement, randomization process, allocation concealment, and implementation were performed by a researcher who was not involved in the study. Random Allocation Software program was used for simple electronically-generated randomization.

Randomization ensured patients' allocation to both groups with 1:1 ratio. Allocation concealment was ensured by using numbered, sealed, opaque envelopes prepared before the trial commencement. The envelopes were sequentially opened only after the envelope had been irreversibly assigned to a participant

\section{Blinding:}

Double-blinding was ensured in this study. Only the chemist who cooperated with us was aware of the distribution of disinfectants. She assigned a number to each bottle that only she was aware of.

\section{Statistical analysis:}

Data were analyzed using SPSS version 22. Distribution of data was evaluated using the KolmogorovSmirnov test. Since data were not normally distributed, non-parametric tests were applied. The Friedman test was used to assess the efficacy of T. vulgaris essential oil and $\mathrm{CHX}$ within each group. The Mann Whitney test was applied to compare the efficacy of T. vulgaris essential oil and CHX. 


\section{Results}

\section{Participant flow}

Of 83 patients, 28 were excluded since they did not meet the eligibility criteria. Of the remaining 55, 44 had removable orthodontic appliances contaminated with $\mathrm{C}$. albicans and were enrolled in the study. Recruitment began in April 2019 and was completed in August 2019. Two participants were later excluded since their orthodontic appliance broke and they did not cooperate well after the trial commencement; The CONSORT diagram is shown in Fig. 1.

\section{Baseline data}

The baseline characteristics for age, sex and the time point at which patients were recruited were similar in both groups (Table 1).

\begin{tabular}{|cll|}
\hline & Thymus vulgaris & Chlorhexidine \\
\hline Age & $10.4 \pm 1.9$ & $9.9 \pm 1.1$ \\
Sex & & \\
Boy & $11(52.38 \%)$ & $13(61.90 \%)$ \\
Girl & $10(47.62 \%)$ & $8(38.10 \%)$ \\
\hline
\end{tabular}

Table 1

Basic characteristics for patients in each groups

\section{Numbers analyzed for each outcome, estimation and precision, subgroup analysis}

For data analysis, the colony count was classified into five groups of rare, few, moderate, many and numerous (Table 2). The Friedman test revealed that continuous use of T. vulgaris essential oil or $\mathrm{CHX}$ significantly decreased the colony count $(P<0.05$, Table 3$)$. The Mann Whitney test showed that this reduction was not significantly different between the two groups of T. vulgaris essential oil and $\mathrm{CHX}$ (Table 3). Figure 2 shows the change in the mean rank of colony count (contamination rate) in the two groups. Although the mean difference in the first and third samplings was the same and equal to 0.1 , the $2 \% \mathrm{~T}$. vulgaris essential oil graph was completely descending, while the $0.2 \% \mathrm{CHX}$ graph reached a plateau from the second phase on. 


\begin{tabular}{|ll|}
\hline Classification & Number of colonies \\
\hline Rare & Number of colonies $<=10$ \\
\hline Few & $10<$ Number of colonies $<=30$ \\
\hline Moderate & $30<$ Number of colonies $<=60$ \\
\hline Many & $60<$ Number of colonies $<=100$ \\
\hline Numerous & Number of colonies $>100$ \\
\hline
\end{tabular}

Table 2

Classification of colony count data

Table 3

Within-group and between-group comparisons of the mean rank of colony count

\begin{tabular}{|c|c|c|c|c|c|}
\hline \multirow[t]{2}{*}{ Groups } & \multirow[t]{2}{*}{ Number } & \multicolumn{3}{|c|}{ Mean Rank } & \multirow[t]{2}{*}{ P value ${ }^{a}$} \\
\hline & & TO & T1 & $\mathrm{T} 2$ & \\
\hline Thymus vulgaris & 21 & 2.50 & 1.87 & 1.63 & 0.002 \\
\hline Chlorhexidine & 21 & 2.60 & 1.67 & 1.73 & 0.001 \\
\hline$P$ value ${ }^{b}$ & & 0.505 & 0.809 & 0.501 & \\
\hline \multicolumn{6}{|c|}{ T0: first day of intervention; T1: Two days after intervention; T2: Five days after interventio } \\
\hline \multicolumn{6}{|c|}{ a. Friedman test; $p<0.05$} \\
\hline b: Mann Whitney & 0.05 & & & & \\
\hline
\end{tabular}

Figure 3 shows the relative frequency distribution of different levels of colony count in the two groups at different time points. The relative frequency of rare class was $6.7 \%$ in both groups at baseline while the frequency of rare class was $53.3 \%$ in the $2 \% \mathrm{~T}$. vulgaris essential oil and $26.7 \%$ in the $\mathrm{CHX}$ group in the final sampling, which indicated higher efficacy of T. vulgaris essential oil than $\mathrm{CHX}$. The relative frequency of numerous class was $80 \%$ in T. vulgaris essential oil group at baseline, which decreased to $40 \%$ in the final sampling. The remaining $40 \%$ was distributed among different classes, with rare class having a higher frequency. This rate was $66.7 \%$ at baseline in the $\mathrm{CHX}$ group, which decreased to $33.3 \%$ in the final sampling. The remaining percentage mainly belonged to the few class, which indicated the superiority of T. vulgaris essential oil to $\mathrm{CHX}$.

\section{Results of GC-MS:}

The interpretation of GC-MS results revealed that the essential oil used in this study contained $43.7 \%$ thymol. Table 4 lists the 14 main constituents of this essential oil. 
Table 4

Main constituents of $\mathrm{T}$. vulgaris

essential oil.

\begin{tabular}{|ll|}
\hline Compound & $\%$ \\
\hline Alpha- Phellandrene & 1.30 \\
\hline Alpha-Pinene & 5.65 \\
\hline Camphene & 1.88 \\
\hline Beta-Pinene & 0.42 \\
\hline Beta-Myrecene & 1.35 \\
\hline Alpha-Terpinene & 0.76 \\
\hline Cymene & 16.96 \\
\hline Gamma-Terpinene & 4.52 \\
\hline Cis-Sabinenehydrate & 1.46 \\
\hline Camphor & 1.16 \\
\hline Borneol & 4.33 \\
\hline Alpha-fenchyl acetate & 0.94 \\
\hline Thymol methyl ether & 1.77 \\
\hline Thymol & 43.7 \\
\hline
\end{tabular}

Harms

No harm was observed or reported from the participants in the study.

\section{Discussion}

Orthodontic appliances can impair the balance of microorganisms in the oral environment and may even lead to disease $[10,11]$. The acrylic base of removable orthodontic appliances is made of polymethyl methacrylate-based auto-polymerizing resin while the wires are made of stainless steel. The pathogenic microorganisms can lodge in resin porosities on the external and internal surfaces of acrylic components. Also, degradation of acrylic resin can cause bacterial biofilm accumulation [13].

The mechanical plaque removal methods such as tooth brushing are suitable for elimination of the accumulated biofilm. Nonetheless, mechanical methods alone are not highly effective in many individuals due to poor motivation or hand skills [43]. Thus, chemical plaque removal agents are always considered along with the mechanical methods. Many chemical and herbal products are used for elimination or reduction of microorganisms [44]. $\mathrm{CHX}$ is the gold standard for chemical removal of the 
microbial plaque. Nonetheless, $\mathrm{CHX}$ is a synthetic chemical agent, which can have many side effects following long-term application [18]. Thus, long-term use of chemical agents is not recommended [15]. In the recent years, the demand for alternative plaque removal methods has greatly increased. Herbal products are gaining increasing popularity due to their organic nature and fewer side effects [27]. The results of this clinical trial showed that T. vulgaris essential oil and $\mathrm{CHX}$ effectively decreased the $\mathrm{C}$. albicans colonies accumulated on orthodontic appliances. In this study, the T. vulgaris plant was collected early in April, and the aerial part of the plant was used to ensure its high quality.

T. vulgaris is a medicinal plant with antimicrobial properties [45]. It has favorable taste and odor and low cytotoxicity [35]. Nonetheless, the in vivo effect of T. vulgaris essential oil on C. albicans isolated from removable orthodontic appliances has not been previously evaluated. According to a study by Kaviani et al, the MIC of T. vulgaris against C. albicans isolated from the surface of acrylic appliances was $1.56 \%$ $(15.6 \mu \mathrm{L} / \mathrm{mL})$ [42]. Thosar et al. reported the MIC of T. vulgaris essential oil to be $1.6 \%(16 \mu \mathrm{L} / \mathrm{mL})$, with the difference that they used standard-strain C. albicans in vitro [24]. Moreover, Fani et al. showed that the MIC of T. vulgaris essential oil was $1.63 \%(16.3 \mu \mathrm{L} / \mathrm{mL})$ [46]. In this clinical trial, $2 \%$ T. vulgaris essential oil was formulated to compensate for the possible procedural errors.

Although immersion of orthodontic appliances in disinfecting solutions for a certain period of time is the conventional method for disinfection of these appliances at home [47], immersions can lead to water sorption and subsequent adverse changes in the acrylic resin structure. In this study, the spraying technique was used instead of immersion to prevent possible changes in acrylic resin structure. Also, spraying is cost-effective and easier for patients $[13,48]$.

The results of this clinical trial revealed that $2 \% \mathrm{~T}$. vulgaris essential oil and $0.2 \% \mathrm{CHX}$ had suitable antifungal effects on orthodontic appliances contaminated with C. albicans. Nonetheless, the reduction in colony count was not significantly different between the two groups.

The antimicrobial properties of medicinal plants mainly depend on the presence and concentration of phenolic compounds, saponins, and flavonoids in their structure. These compounds can adversely affect the plasma membrane of microorganisms or inhibit their structural cell membrane enzymes and exert their antimicrobial effects as such [49].

Thymol and carvacrol are among the main constituents of T. vulgaris essential oil, and the antifungal properties of this plant can be attributed to these ingredients. Carvacrol is an iso-thymol that increases the activity of ATPase and inhibits the activity of the enzyme responsible for non-specific permeability of the cell membrane of microorganisms such as bacteria, and consequently increases their sensitivity to external factors entering the cell [50]. Thus, difference in the MIC of T. vulgaris essential oil can be attributed to the variations in the percentage of its constituents.

Assessment of the mean rank-time graph revealed that continuous use of $\mathrm{T}$. vulgaris essential oil during the study period caused a continuous reduction in C. albicans colony count. However, $\mathrm{CHX}$ caused a reduction in colony count to some extent and then reached a plateau. Also, assessment of the relative 
frequency of $\mathrm{C}$. albicans colonies revealed that $\mathrm{T}$. vulgaris essential oil was more effective than $\mathrm{CHX}$ for reduction of the relative frequency of $\mathrm{C}$. albicans colonies.

\section{Generalizability}

The patients recruited for this study were 10 to 12 years old, this shows the age range for removable orthodontics appliance and allowing the results to be generalized across this age range.

\section{Limitation:}

Short intervention period: to evaluate the effect of prolonged use of T. vulgaris essential oil on oral mucosa and teeth, enlarging treatment duration is necessary. Further studies on the antimicrobial efficacy of T. vulgaris essential oil against other microorganisms accumulated on orthodontic appliances and dentures are required prior to extensive clinical use of this essential oil as an alternative to $\mathrm{CHX}$.

\section{Conclusion:}

Although this study found no significant difference in antifungal efficacy of $2 \% \mathrm{~T}$. vulgaris essential oil and $0.2 \% \mathrm{CHX}$ against $\mathrm{C}$. albicans isolated from removable orthodontic appliances, $2 \% \mathrm{~T}$. vulgaris essential oil can be suggested as an alternative to $\mathrm{CHX}$ for elimination of fungal contamination of orthodontic appliances, considering its lower cytotoxicity, fewer side effects, and higher patient acceptance, compared with $\mathrm{CHX}$.

\section{Abbreviations}

T. vulgaris: Thymus vulgaris; C. albicans: Candida albicans; CHX: Chlorhexidine; GC-MS: Gas Chromatography/Mass Spectrometry; MIC: Minimum Inhibitory Concentration;

\section{Declarations}

\section{Ethics approval and consent to participate:}

This clinical trial was approved by the ethics committee of Islamic Azad University, School of dentistry, Shiraz Branch (Reference:IR.IAU.SHIRAZ.REC.1397.004) and registered in the Iranian Registry of Clinical Trials (Trial registration:IRCT20180923041092N1. Registered 23 November 2019 - Retrospectively registered, https://www.irct.ir/user/trial/34180/view).

\section{Availability of data and material:}

The datasets used and/or analyzed during the present study are available from the corresponding author.

\section{Competing interests:}


The authors declare that they have no competing interests.

\section{Funding:}

No funding was provided for this study.

\section{Authors' contributions:}

NN and TB contributed in the design of the study, wrote the first draft of the manuscript, revised the manuscript, participated in data interpretation, and gained permission from the Medical Ethics Committee, Shiraz branch, Islamic Azad university, Iran. A KK participated in acquisition of data and revision of the manuscript. A KK and RS made contributions to prepare the extract of Thymus vulgaris and mouthwashes. provided critical comments. S N Participated in microbial evaluation and data interpretation. All authors read and approved the final manuscript

\section{References}

1. Littlewood S. J.S J Littlewood, A G Tait, N A Mandall \& D H Lewis. The role of removable appliances in contemporary orthodontics. British Dental Journal. September 2001;191:304-310.

2. Houston WJB, Isaacson KG. Orthodontic treatment with removable appliances. 2nd ed. Bristol, UK: John Wright \& Sons; 1980.

3. Batoni G, Pardini M, Giannotti A, Ota F, Giuca MR, Gabriele M, Campa M, Senesi S. Effect of removable orthodontic appliances on oral colonization by mutans streptococci in children. Eur $\mathrm{J}$ Oral Sci. 2001 Dec;109(6):388-92.

4. Jordan C, LeBlanc DJ. Influences of orthodontic appliances on oral populations of mutans streptococci. Oral Microbiol Immunol.2002 Apr;17(2):65-71.

5. Anhoury P, Nathanson D, Hughes CV, Socransky S, Feres M, Chou LL. Microbial profile on metallic and ceramic bracket materials. Angle Orthod.2002 Aug;72(4):338-43.

6. Lin JJ, Cameron SM, Runyan DA, Craft DW. Disinfection of denture base acrylic resin. J Prosthet Dent.1999 Feb;81(2):202-6.

7. Van Reenen JF. Microbiologic studies on denture stomatitis..J Prosthet Dent. 1973 Oct;30:493-505.

8. Shah AA,Sandler J. Limiting factors in orthodontic treatment: 1 . Factors related to patient, operator and orthodontic appliances. Dent Update. 2006 Jan-Feb;33(1):43-4, 46-8, 51-2.

9. Kabir MA, Ahmad Z. Candida infectionsand their prevention. ISRN Prev Med. $2012 \mathrm{Nov}$ 4;2013:763628.

10. Nobbs AH, Lamont Rj, Jenkinson HF. Streotococcus adherence and colonization. Micribiol Mol Biol Rev. 2009;73:407-450. 
11. Jordan C, LeBlanc DJ. Influences of orthodontic appliances on oral populations of mutans streptococci. Oral Microbiol Immunol.2002 Apr;17(2):65-71.

12. Kundu R1, Tripathi AM, Jaiswal JN, Ghoshal U, Palit M, Khanduja S.Effect of fixed space maintainers and removable appliances on oral microflora in children: An in vivo study $\mathrm{J}$ Indian Soc Pedod Prev Dent. 2016 Jan-Mar;34(1):3-9.

13. Peixoto IT, Enoki C, Ito IY, Matsumoto MA, Nelson-Filho P. Evaluation of home disinfection protocols for acrylic baseplates of removable orthodontic appliances: A randomized clinical investigation. Am J Orthod Dentofacial Orthop 2011;140(1):51-7.

14. Lessa FC, Enoki C, Ito IY, Faria G, Matsumoto MA, Nelson-Filho P.In-vivo evaluation of the bacterial contamination and disinfection of acrylic baseplates of removable orthodontic appliances.Am J Orthod Dentofacial Orthop. 2007 Jun;131(6):705.e11-7.

15. Nayak N, Varghese J, Shetty S, Bhat V, Durgekar T, Lobo R, Nayak UY, U V. Evaluation of a mouthrinse containing guava leaf extract as part of comprehensive oral care regimen- a randomized placebo-controlled clinical trial. BMC Complement Altern Med.2019 Nov 21;19(1):327.

16. Cacciafesta V,Sfondrini MF, Stifanelli P, Scribante A, Klersy C. Effect of chlorhexidine application on shear bond strength of brackets bonded with a resin-modified glass ionomer. Am J Orthod Dentofacial Orthop. 2006 Feb; 129(2):273-6.

17. Moshrefi A. J West Soc Periodontol Periodontal Abstr. 2002; 50(1):5-9.

18. Haas AN,Pannuti CM, Andrade AK, Escobar EC, Almeida ER, Costa FO, Cortelli JR, Cortelli SC, Rode SD, Pedrazzi V, Oppermann RV. Mouthwashes for the control of supragingival biofilm and gingivitis in orthodontic patients: evidence-based recommendations for clinicians. Braz Oral Res. 2014 Jul 11;28(spe):1-8.

19. Yazdani D, Shahnazi S, Jamshidi A, Rezazadeh S, Mojab F. Study on variation of essential oil quality and quantity in dry and fresh herb of Thyme and Tarragon. JMP. 2006;1 (17):7-15

20. Warnke PH,Becker ST, Podschun R, Sivananthan S, Springer IN, Russo PA, Wiltfang J, Fickenscher $\mathrm{H}$, Sherry $\mathrm{E}$. The battle against multi-resistant strains: Renaissance of antimicrobial essential oils as a promising force to fight hospital-acquired infections. J Craniomaxillofac Surg. 2009 Oct; 37(7):3927.

21. Edwards-Jones V,Buck R, Shawcross SG, Dawson MM, Dunn K. The effect of essential oils on methicillin-resistant Staphylococcus aureus using a dressing model. 2004 Dec;30(8):772-7.

22. Khoramian Tusi $S^{1}$, Jafari $A^{2,3}$, Marashi $S M A^{4}$, Faramarzi Niknam $S^{1}$, Farid $M^{5}$, Ansari $M^{6}$. The effect of antimicrobial activity of Teucrium Polium on Oral Streptococcus Mutans: a randomized crossover clinical trial BMC Oral Health.2020 May 1;20(1):130.

23. Fine DH, Markowitz K, Furgang D, Goldsmith D, Ricci-Nittel D, Charles CH, Peng P, Lynch MC Effect of rinsing with anessential oil-containing mouthrinse on subgingival periodontal pathogens. $\mathrm{J}$ Periodontol. 2007 Oct;78(10):1935-42.

24. Thosar N,Basak S, Bahadure RN, Rajurkar M. Antimicrobial efficacy of five essential oils against oral pathogens: An in vitro study. Eur J Dent. 2013 Sep;7(Suppl 1):S71-7. 
25. Yu D,Pearson SK, Bowen WH, Luo D, Kohut BE, Harper DS. Caries inhibition efficacy of an antiplaque/antigingivitis dentifrice. Am J Dent. 2000 Sep;13(Spec No):14C-17C.

26. Arbabi klati F, SHerzaee M, Poorzamani M, Dabiri S. Inhibitory Effects of Plant Extracts Containing Thyme, Clore and Cinnamon Compared to Nystatin On Candida Albicans. (Invitro). J Res Dent Sci. 2012;8 (4):175-179.

27. Karbach J,Ebenezer S, Warnke PH, Behrens E, Al-Nawas B. Antimicrobial effect of Australian antibacterial essential oils as alternative to common antiseptic solutions against clinically relevant oral pathogens. Clin Lab. 2015;61(1-2):61-8.

28. Martins N, Ferreira IC, Barros L, Silva S, Henriques M. Candidiasis predisposing factors, prevention, diagnosis and alternative treatment. 2014;177(5-6):223-40.

29. Pfaller MA, Diekema DJ. Epidemiology of invasive candidiasis: a persistent public health problem. Clin Microbiol Rev. 2007 Jan;20(1):133-63.

30. Seneviratne CJ, Jin LJ, Samaranayake YH, Samaranayake LP. Cell density and cell aging as factors modulating antifungal resistance of Candida albicans biofilms. Antimicrob Agents Chemother. 2008;52(9):3259-66.

31. Kanafani ZA, Perfect JR. Antimicrobial resistance: resistance to antifungal agents: mechanisms and clinical impact. Clin Infect Dis. 2008 Jan 1;46(1):120-8.

32. Worth LJ, Blyth CC, Booth DL, Kong DC, Marriott D, Cassumbhoy M, Ray J, Slavin MA, Wilkes JR. Optimizing antifungal drug dosing and monitoring to avoid toxicity and improve outcomes in patients with haematological disorders. Intern Med J. 2008;38(6b):521-37.

33. Burine D. Wild flowers of Mediterranean. English: Dorling Kinderseley. 1995. 320.

34. Bown D. Encyclopedia of herbs \&Their uses. London: Dorling Kindersley. 1995;253-63.

35. Nabati F, Mojab F, Habibi-Rezaei M, Bagherzadeh K, Amanlou M, Yousefi B. Large scale screening of commonly used Iranian traditional medicinal plants against urease activity. Daru. 2012 Oct $31 ; 20(1): 20-72$.

36. Ozel MZ, Gogus F, Lewis AC. Subcritical water extraction of essential oils from Thymbra spicata. Food Chemistry. 2003;82(3):381-6.

37. Cassel E, Vargas R, Martinez N, Lorenzo D, Dellacassa E. Steam distillation modeling for essential oil extraction process. Ind Crops Prod. 2009;29(1):171-6.

38. Khayat A, Saberi S, Moazami F. Antimicrobial effect of $\mathrm{NaClO}$, Hydrated $\mathrm{Ca}(\mathrm{OH}) 2$, Thyme oil and Normal Saline as irrigating solutions on black pigmented and strep viridance. Shir J Dent. 2003;4(3):19-28.

39. Ahmad J, Masoud K, Mahin N, Ronak B, Yahya B. Comparative evaluation of antiseptic effects of sodium hypochlorite, thyme essence and normal saline in root canal irrigation of primary teeth. $J$ Dental Med. 2014;27(3):161-7.

40. Jafari AA, Falah Tafti A, Hoseiny SM, Kazemi A. Antifungal Effect of Zataria multiflora Essence on Experimentally Contaminated Acryl Resin Plates With Candida albicans. Iran Red Crescent Med J. 
2015;17(1):e16552.

41. Jafari $A$, Aghili $H$, Herandi V.Investigation Antibacterial property of the Zataria Multiflora Essence and Chlorhexidine on Orthodontic Elastic Rings Contaminated with Streptococcus Mutans In Vitro. J Shahid Sadoughi Univ Med Sci. 2013;21(4):514-22

42. Kavianirad F, Bahador N, Naseri N, Baherimoghadam T, Safaeian R. The Antifungal Effect of Thymus Vulgaris on Isolated Candida Albicans from the Surface of Removable Orthodontic Appliances. Herbal Medicines Journal .2019; 4(2):1-10.

43. Kulak Y, Arikan A, Albak S, Okar I, Kazazoğlu E. Scanning electron microscopic examination of different cleaners: surface contaminant removal from dentures. J Oral Rehabil.1997 Mar 24(3):20915.

44. Bishara Se, Damon PL, Olsen ME, Jakobsen JR. Effect of applying chlorhexidine antibacterial agent on the shear bond strength of orthodontic brackets. Angle Orthodontist 1996;66(4):313-16.

45. Ahmad A, Khan A, Akhtar F, Yousuf S, Xess I, Khan LA, Manzoor N. Fungicidal activity of thymol and carvacrol by disrupting ergosterol biosynthesis and membrane integrity against Candida. Eur $\mathrm{J}$ Clin Microbiol Infect Dis. 2011;30(1):41-50

46. Fani M, Kohanteb J.In Vitro Antimicrobial Activity of Thymus vulgarisEssential Oil Against Major Oral Pathogens. J Evid Based Complementary Altern Med. 2017 Oct;22(4):660-666.

47. Pavarina AC,Pizzolitto AC, Machado AL, Vergani CE, Giampaolo ET. An infection control protocol: effectiveness of immersion solutions to reduce the microbial growth on dental prostheses. J Oral Rehabil. 2003 May;30(5):532-6.

48. Sato S,Pedrazzi V, Guimarães Lara EH, Panzeri H, Ferreira de Albuquerque R Jr, Ito IY. Antimicrobial spray for toothbrush disinfection: an in vivo evaluation. Quintessence Int. 2005 Nov-Dec;36(10):8126.

49. Shahnaz H, Hifza A, Bushra K, Khan JI. Lipid studies of Cuminum cyminum fixed oil. Pak JBot 2004;36(2):395-401.

50. Shahsavari N, Barzegar M, Sahari MA, Naghdibadi H. Antioxidant activity and chemical characterization of essential oil of Bunium persicum. Plant Foods Hum Nutr 2008;63(4):183-8.

\section{Figures}




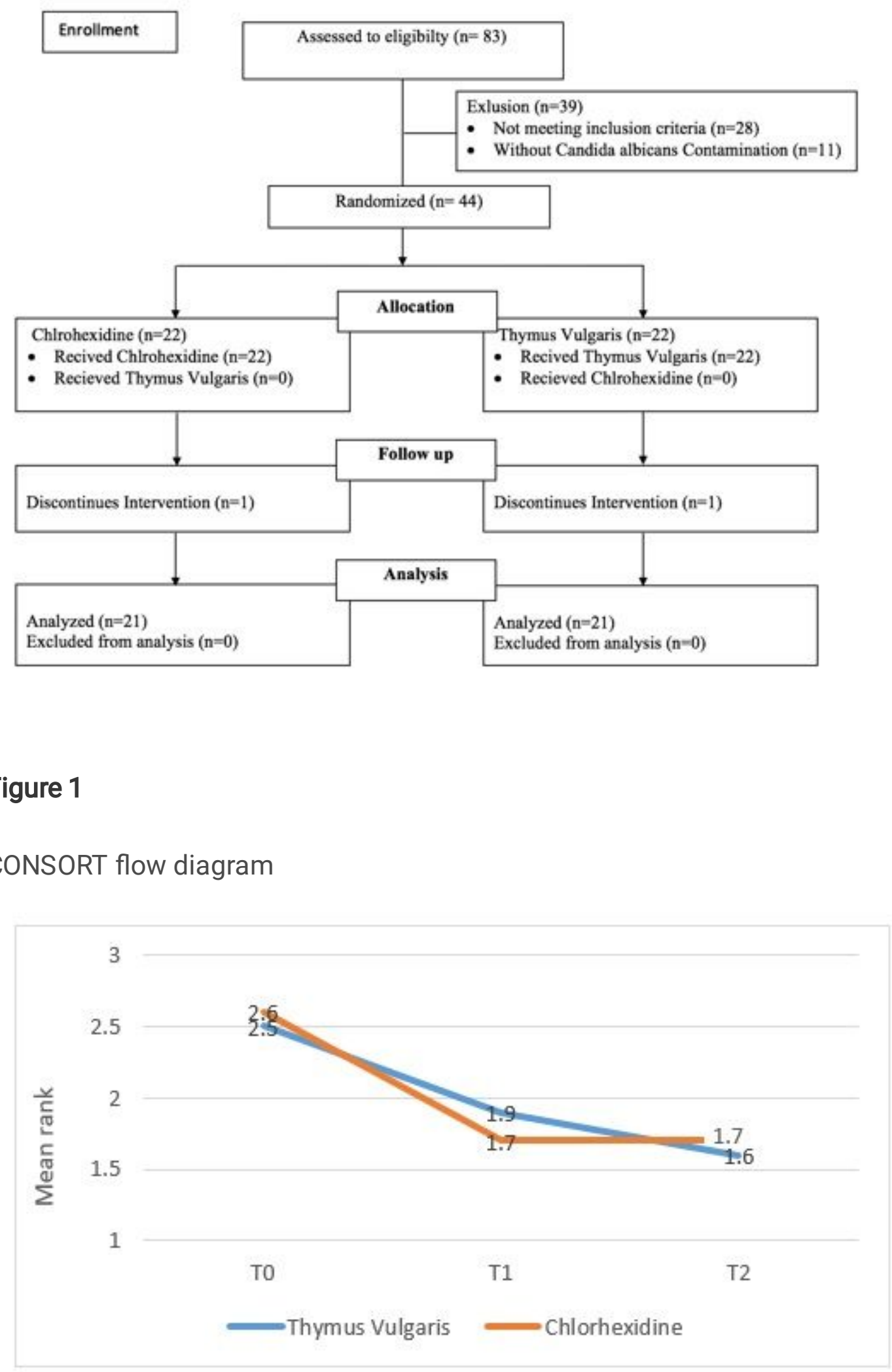

Figure 2 
Change in the mean rank of colony count in the two group s T0: first day of intervention; T1: Two days after intervention; T2: Five days after intervention

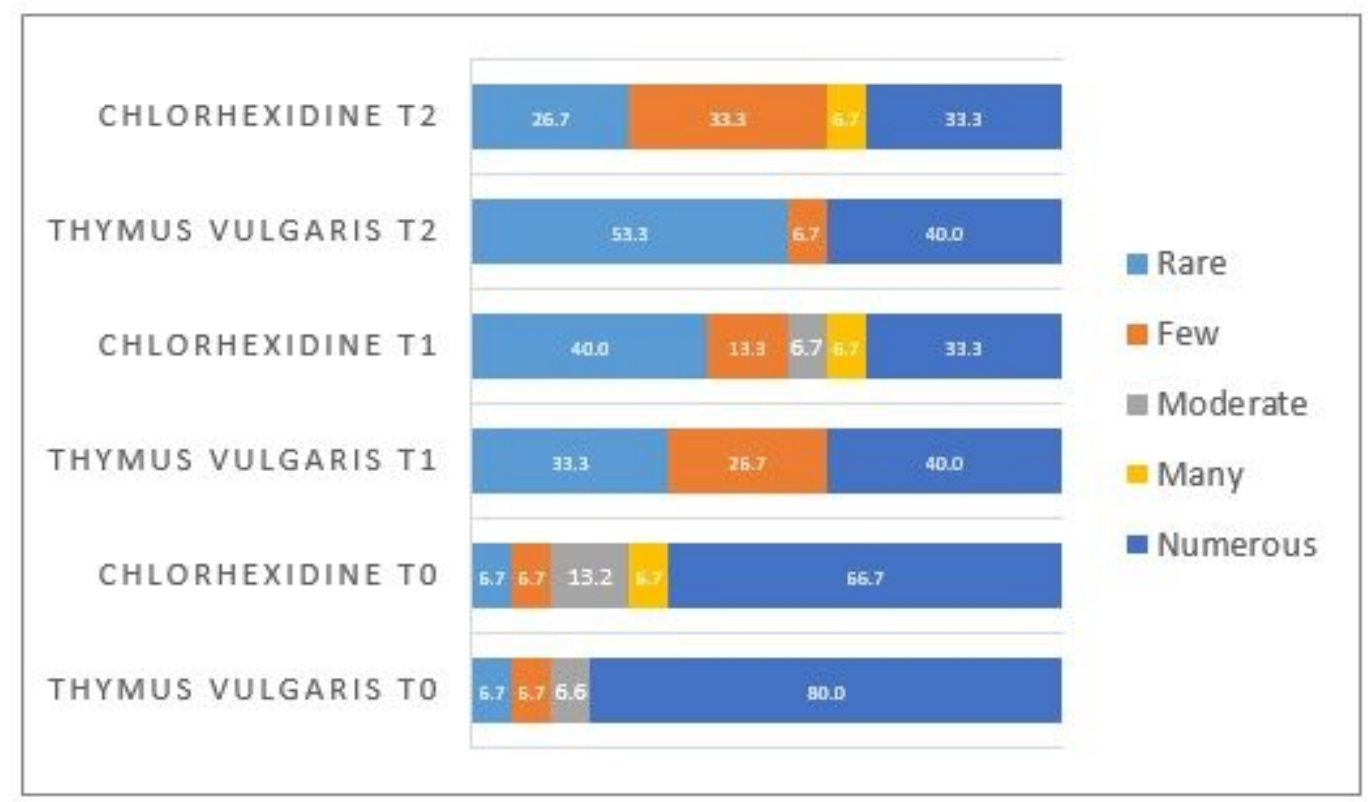

\section{Figure 3}

Relative frequency of different levels of $\mathrm{C}$. albicans colony count at different time points. T0: First day of intervention; T1: Two days after intervention; T2: Five days after intervention.

\section{Supplementary Files}

This is a list of supplementary files associated with this preprint. Click to download.

- CONSORT2010Checklist.doc 